\title{
RESGUARDO INDÍGENA DE UBATÉ: UN SISTEMA DEORGANIZACIÓN Y ADMINISTRACIÓN DEL TERRITORIO EN LA SEGUNDA MITAD DEL SIGLO XVIII EN LA NUEVA GRANADA
}

\author{
Diana Marcela Rubiano Ochoa(a)
}

\author{
INDIGENOUS RESERVATION OF UBATÉ: A SYSTEM OF \\ SPACE ORGANIZATION AND ADMINISTRATION IN \\ THE SECOND HALF OF THE 18TH CENTURY \\ RESGUARDO INDÍGENA DE UBATÉ: UM SISTEMA DE \\ ORGANIZAÇÃO E ADMINISTRAÇÃO DO TERRITÓRIO NA \\ SEGUNDA METADE DO SÉCULO XVIII NA NOVA GRANADA
}

Fecha de recepción: 21 de junio del 2019

Fecha de aprobación: 12 de diciembre del 2019

Disponible en línea: 31 de diciembre del 2019

Sugerencia de citación:

Resguardo indígena de Ubaté: un sistema de organización y administración del territorio en la segunda mitad del siglo XVIII en la Nueva Granada. Razón Crítica, 8, 139-161. doi: 10.21789/25007807.1572

(1) El presente artículo es un resultado parcial de la tesis de grado Resguardo de Ubaté: territorio, sociedad, segregación y reducción en la segunda mitad del siglo XVIII, con la que se opta al título de Magister en Historia en la Universidad Pedagógica y Tecnológica de Colombia -UPTC-. Esta investigación está dirigida por la profesora Blanca Ofelia Acuña.

(a) Diana Marcela Rubiano Ochoa Docente de Aula

Candidata Magister en Historia Universidad Pedagógica y Tecnológica de Colombia, Colombia. dianarubiano.dr@gmail.com https://orcid.org/0000-0002-0118-6850 


\section{R E S U M E N}

El presente artículo aborda el Resguardo de Ubaté entre 1750 y 1800 . Este fue un caso complejo de sistema de organización espacial hispana. Los resguardos fueron modelos de organización social, administración y control territorial, que permitían delimitar y asignar un espacio de tierra a una comunidad indígena con distintos objetivos. Entre estos se identifica el de liberar terrenos mediante prácticas de arrendamiento de tierras a vecinos, como producto del traslado y/o agrupación de los indígenas hacia otros poblados. Adicionalmente, los resguardos permitían proteger y organizar los indígenas para facilitar el adoctrinamiento católico. Se toman como fuentes primarias la información de las dos principales visitas realizadas dentro del periodo por funcionarios de la corona: la de Joaquín de Aróstegui y Escoto, y la de Moreno y Escandón. Estos documentos permiten analizar aspectos al interior del resguardo, como su composición social y estructura, además de reconstruir las líneas principales de los procesos de cambio.

PALABRAS CLAVE: Resguardo indígena, alinderamiento, administración, visitas, territorio. 


\section{A B S T R A C T}

This paper discusses the indigenous reservation of Ubaté from 1750 to 1800 . This was a special case of a complex system of Hispanic space organization. The Indigenous Reservations were models of social organization, administration, and territorial control, which consisted of delimiting and assigning a land space to an indigenous community with different aims. One of these purposes was freeing land through the practice of leasing it to neighbors (third parties). In addition, the reservation allowed the protection and organization of indigenous people to facilitate the catholic indoctrination. This paper uses as primary sources the visit reports of Joaquín de Aróstegui y Escoto, and Moreno y Escandón (Spain royal officers). These documents allow the analysis of internal aspects of the reservation, such as its social composition and structure, and its main lines of changing.

\section{KEYWORDS: Indigenous Reservations, demarcation of lands, administration, visits, territory.}

\section{R E S U M O}

O presente artigo aborda o Resguardo de Ubaté entre 1750 e 1800 . Este foi um caso complexo de sistema de organização espacial hispânico. Os resguardos foram modelos de organização social, administração e controle territorial, que permitiam delimitar e alocar um espaço de terra a uma comunidade indígena com distintos objetivos. Entre estes se identifica a liberação de terrenos por meio de práticas de aluguel de terras a vizinhos como resultado do traslado e/ou da agrupação dos indígenas a outros povoados. Além disso, os resguardos permitiam proteger e organizar aos indígenas para facilitar o doutrinamento católico. Tomam-se como fontes primárias a informação das duas principais visitas realizadas dentro do período: as visitas de Joaquim de Aróstegui y Escoto, e de Moreno y Escandón. Estes documentos permitem analisar aspectos ao interior do resguardo, tais como a sua composição social e estrutura, além de restabelecer as linhas principais dos processos de mudança. 


\section{N T R O D U C C I Ó N}

Desde el periodo colonial, la tierra fue objeto de disputas por su tenencia, uso y explotación. Precisamente, durante la segunda mitad del siglo XVIII por disposición de la Corona española, se implementaron una serie de cambios sobre el derecho a la propiedad de la tierra en todo el territorio de la Nueva Granada. Estas nuevas normatividades estuvieron orientadas a lograr una mayor rentabilidad. Además, fue en este periodo cuando cambió la estructura de la vida comunal indígena en virtud de la reducción y extinción de algunas tierras otorgadas a los pueblos de indios.

La presente investigación sobre el Resguardo de Ubaté surge de la necesidad de indagar sobre lo sucedido en su interior, teniendo en cuenta la dinámica de movilidad y los cambios sociales. Al mismo tiempo, se pretende no pasar por alto los límites a los que fueron sometidos los indios y las relaciones que se tejieron alrededor del Resguardo.

Los apartados que configuran el presente artículo permiten una reflexión en torno al contexto social, la organización y la administración del territorio entre 1750 y 1800 . La investigación está construida a partir de fuentes primarias, que son las que permiten evidenciar la condición del indio y de los vecinos en la época Colonial, ambos protagonistas en la lucha por la tierra, así como los cambios al interior del Resguardo de Ubaté y todo lo que las políticas indianas acarreaban sobre la población indígena.

Con el presente trabajo se pretende aportar al conocimiento de la historia local, en una época marcada por grandes cambios sociales, organizacionales y de administración. De igual manera, se resalta el resguardo como una institución que modela el espacio y la población en el 
marco de una sociedad dual, que, finalmente, va a caracterizar lo que hoy son los municipios cundinamarqueses.

Las fuentes primarias consultadas consisten principalmente en documentos coloniales en los que se registraba información sobre la estructura del resguardo de Ubaté y lo que sucedía en su interior. Específicamente, fueron de gran importancia los informes de las visitas de Joaquín Aróstegui y Escoto y Francisco Antonio Moreno y Escandón, funcionarios de la corona. El primero fue nombrado por la Real Audiencia de Santafé como oidor, mientras el segundo fungió como oidor y alcalde de Santafé. Estas visitas a los pueblos de indios tienen una importancia fundamental en los cambios históricos del Resguardo, ya que obedecieron a las presiones y la imposición de las leyes de España en el siglo XVIII. Fueron ordenadas especialmente para verificar las condiciones de las tierras comunales, los tributos que se pagaban, y para levantar censos poblacionales. Estas "visitas de la tierra” estuvieron enmarcadas en la fase más contundente del reformismo Borbónico ${ }^{1}$. Éste se materializó en la nueva legislación sobre tierras en la que, bajo pretensiones fisiócratas ${ }^{2}$ e intereses particulares, se cuestionó incluso la existencia misma de la institución del resguardo.

En este estudio se aborda el contexto espacio-temporal y el modelo de organización en el siglo XVII, a partir de las dos visitas antes mencionadas: la de Aróstegui y Escoto (en 1756) y la de Moreno y Escandón (en 1779). Estas visitas tenían propósitos definidos, por un lado, permitir reagrupar a los indios, y por el otro, realizar censos poblacionales y establecer una nueva carga tributaria como mecanismo de presión. Este último mecanismo se mostró como el más rentable para la corona.

Algunos estudiosos del periodo colonial como Diana Bonnet Vélez y Martha Herrera han precisado que este fue un periodo donde hubo mucha presión sobre las tierras comunales. En efecto, la transición demográfica, así como los conflictos y la misma carga tributaria serían los detonantes que reavivaron la llama de un periodo álgido por la posesión de las tierras.

Por otra parte, siguiendo a Levi (2017), este estudio permitió corroborar que la sociedad rural no permaneció inmóvil y que los cambios

1 El llamado reformismo borbónico hace referencia al periodo histórico en el que la Casa Borbón de España, a la cabeza de Carlos III, inicia una serie de reformas tendientes a garantizar el máximo lucro de las colonias americanas, para beneficio de la corona.

2 El término fisiocracia se asocia a la teoría económica impulsada por Françoise Quesnay en Francia, en la que se afirmaba que el buen funcionamiento del sistema económico estaría asegurado sin la intervención del Estado. 
al interior del resguardo se produjeron por la dinámica exterior. Entonces "se puede asumir que esta sociedad rural basa sus decisiones y estrategias en una racionalidad limitada de su entorno" (Levi, 2017, p.2).

Los documentos que respaldan la investigación reposan en el Archivo General de la Nación, en el Fondo Visitas Cundinamarca y caciques e indios. En este tipo de estudios coloniales se analizan fuentes documentales para realizar su transcripción paleográfica ${ }^{3}$. Por lo tanto, el presente estudio pretende aportar a la academia en el entendimiento de estos métodos.

\section{EL RESGUARDO DE UBATÉ EN EL SIGLO XVIII}

El resguardo fue la manifestación espacial hispana de un nuevo modelo de organización social, administración y control del territorio. Bajo dicha figura se delimitaba y asignaba un espacio de tierra a una comunidad indígena, con el objetivo de liberar terrenos, que finalmente pudieran quedar vacíos. De este modo, se podía generar rentabilidad para la corona mediante figuras como el arrendamiento. Igualmente, los resguardos servían para proteger y organizar a los indígenas, de modo a facilitar la doctrina católica. En las tierras de resguardo los nativos debían cultivar los productos para su consumo, además de los que debían tributar al encomendero ${ }^{4}$. Tener a los indígenas en un solo espacio también les permitió a los españoles disponer de mano de obra para usarla en sus haciendas a través del concertaje..$^{5}$

De acuerdo con las disposiciones de la Corona a finales del siglo XVI, el resguardo también fue concebido como una manera de reducir a los indígenas a un espacio limitado para que no continuaran viviendo dispersos en grandes extensiones de tierra. De esto se deduce que, a partir de la política de los resguardos, no solo se "protegía a los indígenas", sino que se liberaban tierras para luego rematarlas entre los mismos españoles, generando un nuevo ingreso a las cajas reales (Colmenares, 1999, p.124).

\footnotetext{
3 La transcripción paleográfica es la técnica de leer e interpretar documentos antiguos y darle una estructura entendible al lector tratando de conservar su escritura, abreviaturas y demás signos.

4 El encomendero era un funcionario de las instituciones coloniales encargado de las funciones de enseñar la doctrina católica, defender a sus encomendados (los indígenas) y recibir el tributo. 5 Se entiende como concertaje el contrato mediante el cual un indígena se obligaba a realizar trabajos agrícolas sin recibir salario o recibiendo lo mínimo.
} 
Por otro lado, es necesario aclarar que en los resguardos que se crearon para las comunidades nativas a finales del siglo XVI y comienzos del XVII fue común la práctica de trasladar y agregar pueblos indígenas entre distintas regiones. Este proceder obligaba a vivir a estos pueblos bajo las órdenes del cacique del resguardo reconocido por los españoles, bajo las condiciones de organización y comportamiento impuestos por las comunidades religiosas a través de la doctrina y la evangelización. Tal es el caso del pueblo de Ubaté, al que le fue ordenado la reducción de su poblado, la agregación de comunidades indígenas de la zona y la definición de los parámetros de trazado para la creación del pueblo de indios. Este episodio lo registra un documento de la visita adelantada por el licenciado Bernardino de Albornoz en el que se describe cómo fueron despojados los indígenas de sus casas y bohíos, obligándolos a vivir en otros espacios:

Traten y confieran entre todos el sitio mejor y más cómodo que quieran para dicha población en que aquí están al presente poblados la mayor parte de los indios del dicho repartimiento y otro que sea competente i son a todos [...] recogidos y no apartados ni divididos como están ahora y pueden acudir a las cosas de la doctrina y demás buenas costumbres y oraciones y quemando y derribando para ellos los bohíos y rancherías que tuvieran fuera de dicha población y haciendo de otros uno nuevo en donde lo escogieren. (AGN, 1592)

Las reducciones fueron una política sostenida en todo el Reino de Granada, cumpliendo con la nueva normatividad de ordenamiento, a fin de liberar tierras y quizás rematarlas entre españoles y vecinos para aumentar los ingresos de las cajas reales.

De aquí se puede deducir que la resistencia de las distintas comunidades en los resguardos debió generar fricciones y conflictos. Como lo refiere el documento anterior, la destrucción de sus viviendas no solo supuso la fricción entre encomendero e indígenas sino, paralelamente, la desestructuración de las relaciones de integración étnica que se había desarrollado en cada comunidad y la generación de nuevas estructuras de comportamiento y convivencia.

Hacia el siglo XVIII, para la Corona española, el resguardo debía facilitar y asegurar la mano de obra indígena. Con esto se pretendía facilitar el recaudo de los tributos y de la información requerida en 
cuanto al número de indios que tributaban y las actividades económicas que desarrollaban. De esta manera se podía mantener un mayor control de su producción.

El sistema de resguardos instaurado a finales del siglo XVI y consolidado durante el siglo XVII tuvo mudanzas cruciales a partir de la implementación de las reformas borbónicas de mediados del siglo XVIII. Las transformaciones económicas, sociales y políticas que pretendían las reformas incluían a los resguardos como un mecanismo para lograr una mayor rentabilidad sobre las tierras, tal como lo señala Bonnet Vélez:

En el virreinato de la Nueva Granada y particularmente en el Altiplano Cundiboyacense la política de reagrupación de la población comunal indígena se aceleró a partir de la década de 1750; esto se debió en parte al nuevo ordenamiento social y estatal impuesto por los Borbones; de alguna manera la reforma basada en el recorte de las tierras de los resguardos se hizo con miras a extraer mayores utilidades. (Bonnet Vélez, 2002, p. 26)

Para la asignación de las tierras de resguardo, la Corona estableció como procedimiento la visita de un oidor ${ }^{6}$ de la Real Audiencia y un capitán del Nuevo Reino de Granada a la provincia elegida. A partir de la visita se obtenía "una lista de los indios tributarios de cada pueblo y una relación sobre la extensión de tierras ocupadas por los indígenas” (González, 1992, p. 21). Acogiendo este procedimiento, el Resguardo de Ubaté fue asignado a los indígenas en 1602 y su delimitación, al parecer, se hizo hacia 1635. Ya en la segunda mitad el siglo XVIII, las visitas realizadas por el señor Aróstegui y Escoto (en 1756) y Moreno y Escandón (en 1779) plantearon inicialmente una nueva delimitación de las tierras de resguardo, para finalmente proceder a su posterior liquidación.

\section{DESCRIPGIÓN DEL RESGUARDO DE UBATÉ}

Ubaté se ubica en lo que se conoce actualmente como el Altiplano Cundiboyacense, un espacio geográfico situado al norte del departamento de Cundinamarca, en la parte central del Virreinato de la Nueva Granada durante el periodo colonial. El Valle de Ubaté ha sido reconocido 
por la presencia de suelos muy fértiles, aptos para la ganadería y agricultura extensivas.

Las tierras del Resguardo de Ubaté formaron parte de la zona del valle conocido con el mismo nombre, el cual se ha caracterizado por su riqueza geográfica y de sus suelos, lo que lo hizo tan atractivo para cultivar. La fertilidad de las tierras propició que Ubaté, durante el periodo colonial, fuera uno de los territorios con mayor productividad. Esto lo convirtió en centro de abastecimiento de productos tan importantes como el trigo, la harina y los derivados de la ganadería, de los cuales se hablará más adelante.

Con respecto a las tierras del Resguardo de Ubaté, se debe señalar que se cumplió con la misma normatividad de delimitación y asignación de todos los demás resguardos. Ésta consistía básicamente en la delimitación de zonas para el cultivo y producción de ganado, y otras para el poblamiento de los indígenas, como lo describe Martha Herrera:

Con la asignación de resguardos el espacio de los pueblos de indios quedó dividido en dos áreas: la del poblado propiamente dicho, en donde los indios debían residir en forma permanente, y la del resguardo, para sus cultivos y cría de sus ganados. Usualmente los resguardos se demarcaron rodeando al caserío, de tal forma que quedaron formando especies de islas alrededor de las cuales los "españoles" pudieron componer con la Corona las tierras realengas para establecer sus estancias y haciendas. (Herrera, 1996, p.167)

En el sitio de poblado o pueblo de indios, los indígenas eran obligados a vivir "en policía española”, es decir, bajo las costumbres y la organización hispana (Colmenares, 1999, p. 201). Por esta razón, se debía construir una capilla doctrinera a donde los indígenas debían asistir para ser adoctrinados y escuchar la misa todos los domingos. Allí también se les ordenaba construir sus casas alrededor de la plaza central, siguiendo el sistema ajedrezado introducido por los españoles. Dentro de las tierras de resguardo, según las indicaciones de la Corona, no se permitía que vivieran blancos ni mestizos. Por esta razón los poblados pasaron a conformar los grupos de vecinos pobres.

Igualmente, fue común que los vecinos se establecieran en tierras aledañas al resguardo como intrusos. Esta práctica no fue ajena al Resguardo de Ubaté, como lo muestra la siguiente denuncia: 
Alberto López Lugo corregidor del partido de Ubaté parezco ante vuestra alteza y digo que con motivo de la introducción de blancos y a otros a quienes les es prohibido hacer mansión en pueblos de indios [...] y lo perjudicial que es a los naturales [...] ni en conformidad de la ley real ha querido remediar semejante introducción de forasteros no lo ha podido conseguir por oponerse a ello algunos sujetos y para que lo puedan practicar con mayor esmero a vuestra alteza lo suplico de mandar se libre prohibición sobre el referido asunto y que sea el fin respecto a los requerimientos percevidos. (AGN, 1746)

El documento anterior deja claro que el corregidor denunciaba los perjuicios que generaba la intromisión de los mestizos y blancos a los resguardos, tales como los constantes pleitos con los indígenas por la apropiación de sus tierras.

En Ubaté ha sido reconocido el caso de la familia Másmela quienes, a través de la encomienda que les fue asignada entre 1578 y 1580, se hicieron propietarios de las tierras aledañas al resguardo. Estos terrenos se consolidaron posteriormente como la hacienda de Niuque, de la cual era propietario Francisco Domínguez, el mayor hacendado aledaño a las tierras del resguardo?

Es paradójico que en un primer momento don Francisco Domínguez se apoderara de una parte de las tierras del resguardo y luego la donara a los indios, no se sabe bajo qué figura. Al parecer los indios la recibieron y la pusieron en arrendamiento. Al parecer, este "noble" gesto no sería nada más que una forma de regresar las tierras que habían sido del resguardo, como puede leerse en el siguiente aparte:

Los gobernadores de este pueblo a nombre de toda la gente nos presentamos ante vuestra excelencia y decimos que el sr. Francisco Domínguez nos hizo donación y gracia de un pedazo de tierra que fuera de nuestros propios resguardos que pertenecía a la hacienda llamada del Niuque que confina con nuestros resguardos como consta en la escritura de donación. (AGN, 1789)

7 En lo referente a la invasión de tierras, ver por ejemplo: AGN. Sección Colonia. Cucunubá: Títulos propiedad, demandas por dinero, pleitos, escrituras. MISCELANEA:SC.39,119,D.19.1788. En este documento se nombran los límites de las tierras aledañas a la hacienda el hato de Rojas, además de pleitos existentes. Ver también: AGN. Sección Colonia. Capellanías-Cundinamarca:SC.9 - CAPELL-C/MARCA:SC.9,3,D.20. 1791. Se trata del documento mas completo sobre las propiedades del Señor Dominguez y la manera como manejaba los recursos. En este documento se puede evidenciar las cuentas dentro de las propiedades y la evolución de la tierra. 
No fue posible establecer los motivos reales por los cuales las tierras arrebatadas por el dueño de la hacienda de Niuque fueron devueltas a los indígenas, pero es posible que se tratara de evitar un pleito que terminaría afectando aún más sus intereses.

Hacia el año 1770 se dio un cambio fundamental en la organización de los resguardos, como señala Tovar:

Se combinó la política de segregación de varios pueblos, mientras que Aróstegui y Escoto procedió básicamente a segregar tierras para rematarlas, venderlas, arrendarlas o canjearlas; por su parte en la década del 70 Moreno y Escandón, y Campuzano y Lanz buscaron defender y practicar la política de trasladar pueblos y rematar las tierras vacantes entre los vecinos, que desde fuera y dentro de los resguardos presionaban para que se despojara fuera de ellas a las comunidades. (Tovar, 1982, p.45)

\section{ALINDERAMIENTO DE TIERRAS DEL RESGUARDO DE UBATÉ}

Debido a que aún no se contaba con métodos sistemáticos de demarcación, para el alinderamiento de las tierras del resguardo, los españoles recurrieron a la utilización de límites naturales como pantanos, montañas, quebradas, ríos, etc. El establecimiento del lindero delimitaba el uso del suelo y, por lo tanto, el derecho de propiedad sobre éste. De este modo, se evitaba que los intrusos usaran las tierras de las comunidades indígenas, pero a la vez establecía un límite entre los indígenas y el poblamiento hispano.

La delimitación del resguardo de Ubaté se remonta al año 1592, cuando se empezaron a congregar los indios en un nuevo poblado, manteniendo las características y ordenanzas de la Corona. Luego, a finales del siglo XVI, estas agregaciones y traslados ocasionaron el desarraigo de los indígenas de su lugar de origen, así como el inicio de procesos de adaptación y convivencia con otros grupos indígenas de poblados vecinos.

De acuerdo con los datos que suministran las visitas en el periodo transcurrido entre 1755 y 1775 , aunque los naturales obedecieron las disposiciones sobre el desarraigo, continuaron manteniendo la 
explotación de algunas tierras originales. La política de reordenamiento de los resguardos fue convirtiéndose en un fenómeno generalizado de agregación de población y de venta de tierras y solares desocupados.

En el siglo XVIII, el nuevo proceso de demarcación y alinderamiento contribuyó con la política de segregación, al tiempo que sirvió como referente para reconocer los derechos de propiedad a los particulares que se hallaban en los límites de las tierras de resguardo. Para el alinderamiento del resguardo de Ubaté, a mediados de este siglo, el visitador don Francisco Antonio Moreno y Escandón, al parecer, retomó la delimitación que se había hecho en 1603. En ésta se establecía que el límite era el pantano y que, por lo tanto, los indígenas no tenían derecho a las islas que se hallaban en su interior. Lo anterior se evidencia en el siguiente aparte del informe presentado por el teniente corregidor Josef de la Torre, quien se encargó de avalar los límites de este resguardo:

Según la porción y repartimiento hecha por el señor presidente, gobernador y capitán general de este nuevo Reino en trece de diciembre de mil y seiscientos nueve los linderos de los mencionados resguardos fueron las orillas del pantano sin que dentro de él se les asignase una vara de tierra prescindiendo por ahora de los términos de dichas millas de que pudiera hacer uso y estableciendo como límites a los pantanos y tierras del Niuque y era a la mano derecha del referido mojón de piedras bajando del río de Ubaté hasta su desagüe en el de Lenguazaque. (AGN, 1800)

En 1755, con la visita de Aróstegui y Escoto, se volvieron a delimitar las tierras del resguardo de Ubaté, siguiendo las aspiraciones y el proyecto de control político de los Borbones. De este modo, fue retomando el pantano como el punto de referencia para la delimitación. Esto se ilustra en un mapa del Valle de Ubaté de finales del siglo XVIII, en el que, además de estas tierras, se aprecian las propiedades de los vecinos y las haciendas de la región que limitaban con el resguardo, así como los caminos que lo conectan con los poblados vecinos (ver figura 1).

En el mapa de 1797 se señala con el número 1 el pantano como centro del resguardo. A cada lado de éste se encontraban las tierras que cultivaban los indígenas. Estas estaban limitadas hacía el norte por el cerro del Niuque (número 15), al sur por la Capellanía de Palacio (número 2), al poniente por la hacienda de propiedad de Agustín Venegas (números 6 y 7), y al oriente por parte del pantano y las peñas 
de la Capellanía de Palacio (número 3). Cabe aclarar que en este mapa histórico se señala con el número 9 la casa de la hacienda Tausavita, de propiedad de Manuel Venegas, hermano del señalado Agustín. Este terreno, al parecer, había sido arrebatado de las tierras del resguardo de Ubaté, pero no se encontró documento alguno al respecto. Lo que sí se menciona es que los límites del resguardo iban hasta el pueblo de Ubaté, señalado en el mapa con el número 11, el cual podría coincidir con el límite natural del río Suta. Acogerse a esta información implicaría que las tierras que se delimitaron como resguardo en el siglo XVII tenían una mayor extensión que las que se señalaron en 1755. Estas incluían las de Tausavita ${ }^{8}$ las haciendas de los hermanos Miguel y Agustín Vanegas, quienes, al parecer, en el transcurso del siglo XVIII, se las habrían apropiado. Esto habría ocasionado conflictos y discordias por las aguas del pantano, el río y el paso de las bestias de propiedad de Agustín Vanegas por las tierras de labranza de los indígenas.

Figura 1. Mapa de las regiones de Cucunubá, Ubaté y pantano de Peña Palacio (1797).

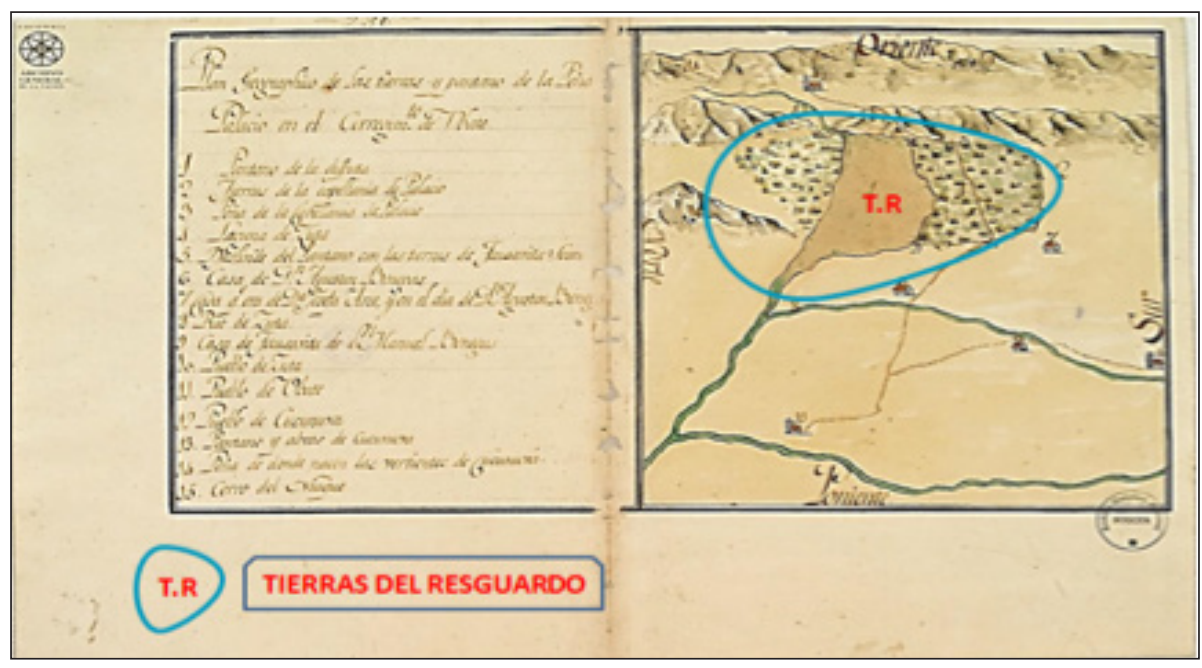

Fuente: AGN, 1797, Sección Mapas y Planos. Ref.: 328A.

8 Las tierras de Tausavita, a las cuales se refiere el mapa, actualmente son de propiedad de una familia de apellido Quintero. Según un vecino del sector, fueron compradas hace más de 30 años pero los propietarios no viven allí. No fue posible lograr una entrevista con los encargados de la casa, quienes manifestaron que no estaban autorizados para conceder ningún tipo de entrevista o acceso al predio. 
Desde una perspectiva histórica, los linderos servían como punto de referencia para la demarcación de un territorio ante la ausencia del Estado. Esto permitió que se diera la oportunidad de apropiación a actores externos como los hacendados. Incluso el establecimiento del resguardo y la demarcación de los límites determinaban las atribuciones de sus funcionarios.

\section{LAS VISITAS DE LA TIERRA EN EL SIGLO XVIII}

La política de reformas sobre la tierra entró en su punto más álgido hacia mediados del siglo XVIII, cuando se promulgaron toda suerte de políticas para la explotación y administración de las colonias hispanas, con el fin de generar más ganancias para la Corona. Esta situación modificó totalmente el orden en la Nueva Granada y, en particular, la dinámica estructural de los resguardos indígenas.

Para el caso del "Virreinato de la Nueva Granada y particularmente en el Altiplano Cundiboyacense, la política de reagrupación de la población comunal indígena se aceleró a partir de la década de 1750" (Bonnet Vélez, 2002, p. 26). Esto influyó directamente en la idea de imponer un nuevo ordenamiento social y estatal. Diversos argumentos eran esgrimidos para iniciar una nueva delimitación de las tierras o para extinguir definitivamente el resguardo. Entre estos se encontraban la disminución de la población indígena o la mala utilización de las tierras de resguardo. Bajo estas justificativas se permitía liberar los terrenos para que posteriormente fueran rematados.

Una de las estrategias usadas por los españoles para implementar las políticas segregacionistas en los resguardos fueron las visitas. Ordenadas por la Real Audiencia de Santafé a partir de la segunda mitad del siglo XVIII, estas visitas coincidieron con el periodo más contundente del reformismo Borbón, y estuvieron influenciadas por una serie de nuevas legislaciones entorno al poder sobre la tierra. Como se vio con anterioridad, esta política de visitas tenía como finalidad reagrupar a los indígenas, determinar el número de naturales y tributarios, y establecer la nueva carga tributaria. Este hecho pesó a favor de la Corona al restablecer la utilidad y la riqueza de las tierras.

Generalmente, cada visita implicaba un procedimiento para la realización de un padrón. En éste participaban tanto las autoridades españolas como los representantes de los indígenas y el protector de 
naturales. Además, era importante contar con información veraz y detallada sobre la población indígena y su capacidad tributaria, pues a partir de las visitas se tomaban decisiones importantes para la vida del resguardo, tales como la determinación de la tasa de tributos y de los linderos, bajo la supervisión del protector de naturales 9 .

$\mathrm{Al}$ respeto Bonnet Vélez señala que:

Después de recibida la cédula real de 1774 se hacía necesario el traslado de los pueblos de indios y la agregación de varios a un mismo resguardo, se argumentaba la falta adecuada del uso de tierras por los indios, los arriendos ilegales de espacios territoriales del resguardo a la población mestiza y blanca que carecía de propiedades y la necesidad de ubicar a estos nuevos pobladores del Altiplano, que ahora superaban numéricamente a la población indígena, y ejercían una fuerte presión sobre las autoridades. (Bonnet Vélez, 2002, p. 23)

Para el caso del Altiplano, estas visitas toman mayor fuerza con el arribo de Andrés Verdugo y Oquendo, primer visitador en llegar a la región de Ubaté hacia 1750. Verdugo y Oquendo "se mostraba reacio a emprender agregaciones de pueblos de indios, prefiriendo mantener a los naturales, en parte de sus resguardos recortando los terrenos más aislados y poniéndolos a la venta entre los 'vecinos' del lugar” (Bonnet Vélez, 2002, p.25). Aparentemente, este gesto podría interpretarse como una señal de benevolencia, en tanto una manifestación del interés de "proteger" a los indígenas. Sin embargo, como lo refieren los documentos, la rentabilidad del resguardo fue más importante que las políticas "benefactoras" de la época. De hecho, luego de las visitas fueron entregadas tierras a los vecinos, ya fuera en calidad de arrendamiento o como justificación de la necesaria reducción del resguardo y la posterior agregación de comunidades indígenas. Dicho de otro modo, las necesidades de los vecinos estaban por encima de los pueblos de indios. De este modo, los primeros resultaban siendo los mayores beneficiados entre los que no tenían tierras para cultivar.

9 El protector de naturales era el encargado de representar a los indígenas y atender el bienestar de las poblaciones nativas ante la autoridad competente. En un comienzo, este oficio estuvo a cargo de los curas. Posteriormente, como en el caso del resguardo de Ubate, estuvo a cargo de un cacique indígena. Esta representación se daba ante el Encomendero. 
En la metodología usada por los visitadores se tuvieron en cuenta las entrevistas con los indios. Éstas se efectuaban por medio de unos cuestionarios preestablecidos, a partir de los cuales se pretendía determinar si se había cobrado más en la tributación por parte de los diezmeros ${ }^{10}$, y si dentro de los resguardos habían vivido personas diferentes a los indígenas, ya fueran mestizos, blancos o de otras etnias.

Los visitadores también indagaban sobre la permanencia de concertados en las tierras del resguardo, y si habían recibido maltrato de los españoles o de otras personas. Dentro de las respuestas de la mayoría de los indígenas se señalaba no saber de maltratos o excesos en el cobro de tributos. No obstante, se presentó una denuncia por parte del protector de indios sobre los linderos en la parte plana del resguardo, la que obligó a los principales del pueblo y la comitiva del señor oidor a realizar la verificación y establecer un nuevo lindero frente a las pretensiones de los indios.

La visita realizada por don Joaquín de Aróstegui y Escoto en 1756 duró alrededor de dos años, durante los cuales se recogieron diversos testimonios de la situación dentro de los resguardos y se determinó cómo podían obrar en su defensa. Posteriormente se hizo una descripción detallada de los indígenas, en la que se incluyeron datos como sus edades, sexo, y la cantidad de tributarios y no tributarios. Los documentos coinciden en que era necesario que durante la visita estuvieran presentes los capitanes de los resguardos y el gobernador del pueblo. Esto permitía establecer cuánta tierra tenían los indios, así como la agregación de algún pueblo cercano para dejar las tierras vacantes, con el objeto de poderlas vender o arrendar a algún particular.

Como ya se ha explicado, en el nuevo Reino de Granada en general, y en particular en Ubaté, los resguardos se adjudicaban a una comunidad de indígenas para que los habitaran y explotaran con fines tributarios. Como lo demuestran los documentos, estos predios eran fértiles, aptos para la agricultura, y se ubicaban muy cerca de los nuevos poblados españoles. Esto permitía tener un mayor control y disposición de la mano de obra indígena. Estas características del terreno las dejarían de manifiesto los visitadores de las tierras, como uno de los objetivos de la administración colonial y como un "atractivo" territorial.

10 Persona que paga, aporta y contribuye a un diezmo. El diezmo puede tratarse de un gravamen en el que se pagaba al rey el $10 \%$ el valor de una mercancía. Igualmente, puede referirse a un aporte $\mathrm{u}$ ofrenda para el sostenimiento de cualquier institución, ya sea la iglesia, la escuela u otras. 
Como en casi todo el territorio, estas reformas permitieron que se despojara legalmente a los indígenas de sus tierras ancestrales, al darles la posesión más no la propiedad. Por parte de los pueblos indígenas, hasta el último momento y estando al límite del remate de sus resguardos, hubo plena "resistencia" a ser despojados. En el concepto de la Corona, estos terrenos eran suficientes para que las comunidades desarrollaran sus actividades agrícolas. "Las tierras que se quitaron a los indígenas se declararon realengas, es decir de propiedad de la Corona, y se pusieron a disposición de los particulares que quisieran componerlas o, en otras palabras, comprárselas a la Corona” (Herrera, 2002, p.166).

La reforma hecha al resguardo a raíz de la visita de Moreno y Escandón permitió reagrupar a los indígenas y establecer la nueva carga tributaria, para cumplir con las disposiciones de la Corona en términos de rentabilidad. No obstante, claramente se evidencia que estas políticas ilustradas estaban decayendo, mientras el proyecto colonial se tornaba más fuerte.

La visita de Moreno y Escandón fue la más contundente en su incidencia en las reformas sobre la propiedad de las tierras indígenas y en los cambios sobre los modos de organización. Para el caso de Ubaté, estas prácticas se justificaban bajo el argumento de la disminución de la población indígena, lo que incentivaba su traslado. De la misma manera, fue obvio que al disminuirse el número de indígenas se redujo también el tributo, lo que motivó a los visitadores a recortar los resguardos y trasladar algunos pueblos de indios.

Hacia 1750, el resguardo de Ubaté ya había sufrido modificaciones en cuanto a su composición social, pues los vecinos y mestizos se ubicaron en sus inmediaciones. Estos nuevos pobladores no tenían la intención de adquirir un pedazo de tierra para cultivarla, sino que pretendían establecer allí su sitio de residencia. Magnus Mörner (1963), en su estudio sobre la política segregacionista en el Nuevo Reino de Granada, explica que los intereses diferentes a los de cultivar la tierra por parte de otras personas ubicadas en predios aledaños a los del resguardo se constituyeron en uno de sus mayores problemas. La presión sobre la tierra, la disminución de la población indígena, la fuga de algunos nativos y el aumento de la población mestiza, fueron los elementos que influyeron en que las tierras vacías se arrendaran a particulares, aumentando la intromisión en los terrenos de los indígenas. 


\section{LA ADMINISTRACIÓN DEL RESGUARDO DE UBATÉ: EL CORREGIMIENTO DE INDIOS O PARTIDO EN EL SIGLO XVIII}

Para el siglo XVIII la provincia de Santafé, entidad administrativa y territorial de la Nueva Granada, se había dividido en siete corregimientos de indios, también llamados partidos: Zipaquirá, Guatavita, Bogotá, Ubaque, Bosa, Pasca y Ubaté (ver figura 2), este último a cargo de un corregidor de indios o de naturales.

Figura 2. Mapa de los corregimientos de la Provincia de Santafé

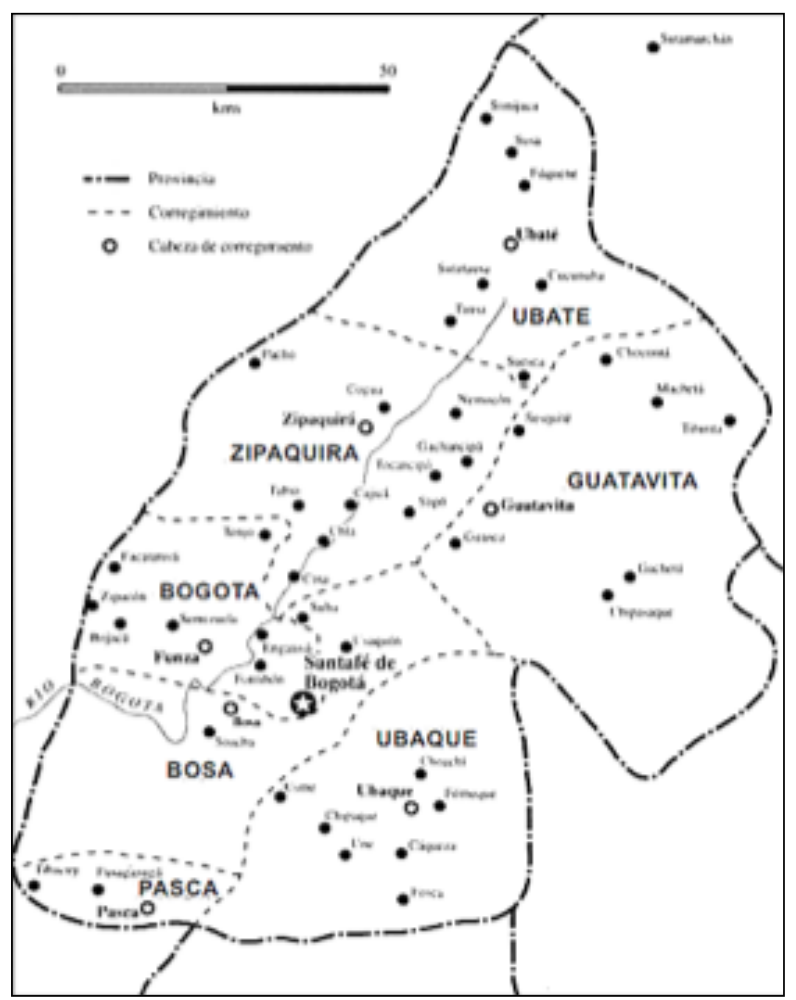

Fuente: Herrera (2002, p.23).

Tanto el corregimiento de Zipaquirá como el de Ubaté conformaban una unidad económica de amplia influencia sobre la provincia de Santafé. Esta región limitaba al norte con el corregimiento de Sáchica, al oriente con el de Guatavita y al sur con los de Bosa y Bogotá (Herrera, 2002, p.277). Si bien el corregimiento representaba una especie de unidad 
administrativa cuyo fin era el de organizar espacialmente la república de indios, el centro de éste era el lugar de residencia del corregidor.

La recolección del tributo y la coordinación del alquiler de los indios quedaron a cargo del corregidor de naturales. Es decir que la creación misma de este cargo estuvo inscrita en la "regulación que hizo el Estado del modelo dual de segregación, que establecía diferentes espacios, obligaciones políticas y económicas y hasta cierto punto, autoridades indígenas y españolas. La figura del corregidor siguió vigente durante mucho tiempo" (Herrera, 2002, p.235).

El corregimiento, como unidad administrativa, desempeñaba una amplia gama de funciones que, como ya se dijo, cobijaban desde lo policivo, la producción, el comercio y la fiscalidad, hasta la administración de justicia y un adecuado manejo religioso de la población. A propósito, un documento del Partido de Ubaté en el que se nombra al Corregidor de Indios para el año de 1657 deja ver los intereses de ocupar tan alta dignidad, además de dar estricto cumplimiento a su función. Como el cargo había quedado vacante, el nombramiento fue solicitado por don Dionisio Manrique, Presidente General y gobernador del Nuevo Reino de Granada:

Digo que por cuanto ha vacado el corregimiento del partido de Ubaté conviene nombrar persona de las partes y calidades necesarias y por concurrencia en don Pedro de Mendoza, se nombrara y nombro por corregidor del partido de Ubaté por tiempo de dos años más o menos la voluntad de su señoría ocho años y poner a su cargo y contarle el tercio de navidad de [...] y para que cobre los requintos de forajidos, mulatos y zambos y alcabalas a deber a su cargo y por lo que toca a las demoras de los encomenderos [...] pago en reales dentro del cargo hoy día de don Pedro de Mendoza a quien el señor presidente y capitán de este Reino ha nombrado por corregidor de naturales del partido de Ubaté 37 patacones. (AGN, 1657)

La función básica del corregimiento era la de reunir pueblos de indios bajo la protección de la figura del resguardo. De este modo se unificaba y centralizaba su administración. El corregimiento de Ubaté reunía los territorios de Susa, Simijaca y Cucunubá. Geográfica y administrativamente este corregimiento fue importante, 
primero porque se encontraba ubicado en todo el centro de la Nueva Granada convirtiéndose en el sector más poblado y diverso, además que encajonaba el camino que iba de Santafé a Chiquinquirá, lugar este que además de ser un centro religioso de importancia estaba ubicado en un sitio estratégico desde el punto de vista de los mercados, por ser camino obligado hacia la vertiente occidental de la cordillera; un solo corregidor con sede en Zipaquirá controlaba Ubaté a través de un teniente general de corregidor. (Herrera, 2002, p.36)

Como se deduce de la cita anterior, la riqueza de Ubaté se relacionaba con la fertilidad de sus tierras. Desde los tiempos de la Conquista, los cronistas afirmaban que la zona del Altiplano era rica y fértil, además de tener una ubicación estratégica en materia de mercados, por ser camino obligado hacia la vertiente de la cordillera occidental. Debe resaltarse además la importancia de esta vía en las comunicaciones con la región de Vélez, importante región del actual departamento de Santander. Esta región se destacaba por ser el centro de acopio de los productos que salían de Ubaté, así como de ser un centro de producción artesanal.

La administración del pueblo empezó a descansar básicamente en los curas, las autoridades indias y los alcaldes pedáneos. La configuración de la autoridad civil remite a dos tipos de pobladores: los indios, que estaban sujetos a sus caciques, gobernadores, capitanes, tenientes, alcaldes y alguaciles indios; y los blancos, que quedaban sujetos a los alcaldes pedáneos. Una tercera autoridad, los curas doctrineros, ejercía sus funciones sobre todo tipo de pobladores. Se conoce que el papel de estos últimos, además de evangelizar a los indígenas, era la mediación y "apaciguamiento" ante los conflictos entre indios y vecinos. Por otra parte, fue clara la figura del corregidor, quien ejercía su autoridad administrativa en el resguardo por medio de subalternos internos, como el teniente o el gobernador, quienes eran allí las máximas autoridades.

No es sorprendente la disminución de la población indígena durante el siglo XVIII en una región de la provincia caracterizada por la presencia y el crecimiento de las haciendas y de las actividades económicas paralelas. Según lo señala Mörner, en los siglos XVII y XVIII los pueblos de indios del centro del Virreinato tuvieron un decrecimiento de su población a favor de la población mestiza (Mörner, 1963).

Por otro lado, todas las políticas españolas se vieron reflejadas en los patrones de organización, como el establecimiento de las zonas o linderos de los resguardos. Estas reformas organizativas son un resultado 
fundamental de las visitas que daban cuenta de las condiciones de funcionamiento del resguardo, su composición y la disposición en él de mano de obra, entre otros aspectos. Asimismo, el modelo de organización basado en un funcionario real como el corregidor, el trazado del nuevo poblado y la forma de reagrupar y reorganizar a los indígenas en esta congregación, se adelantaron en aras de fortalecer la recuperación de espacios "libres". Esto permitió que dichos espacios fueran aprovechados por vecinos aledaños a las tierras del resguardo.

\section{CONCLUSIONES}

Este artículo ha pretendido brindar una modesta contribución a la historia en dos direcciones: por un lado, al debate sobre la composición social durante el periodo colonial en el centro del Virreinato de la Nueva Granada, específicamente a mediados del siglo XVIII. Por otro lado, llama la atención sobre circunstancias históricas relativas al entendimiento del problema del acceso a la tierra.

El análisis territorial y social de la región de Ubaté a finales del siglo XVIII permite destacar aspectos tan importantes como la organización señorial y la posterior organización del resguardo como resultado de las políticas borbónicas. El estudio de la implementación de dichas políticas a través de las visitas de la tierra da cuenta de la composición y distribución física del resguardo, de sus formas de administración y de control del territorio. Además, el estudio informa cómo el hecho de tener a los indios en un solo espacio les permitió a los españoles no solo disponer de tierras, sino aprovecharlas como objeto de venta o arriendo a particulares (vecinos).

Estos procesos de repartición de tierras, en calidad de arrendamiento o simplemente por venta, fue un proceso cargado de conflictos interminables en el intento de la corona por privatizar los resguardos. Además, se debe mencionar que, hacia la primera mitad del siglo XIX, la medición de los límites de los resguardos y la forma como las parcelas de estos iban a ser distribuidas fueron mermando el poder de los indígenas. De este modo, se les permitió a los agrimensores (encargados de delimitar los resguardos) abusar y actuar de una manera poco honorable.

Si bien esta investigación centra su periodo en la segunda mitad del siglo XVIII, es necesario abordar algunos aspectos que servirán para entender como continuó este proceso de liquidación de tierras de 
resguardo, lo que servirá para futuros análisis más detallados iniciando el siglo XIX. Infortunadamente, en la revisión de fuentes documentales no se encontró material que diera cuenta de estas situaciones para dicho periodo.

En la actualidad, en la zona alta de Ubaté existen indígenas que habitan en tierras de resguardo. Sin embargo, como se evidencia, la legislación de protección a los indígenas y sus tierras no es respetada. La tradición oral de sus ancestros da cuenta de la lucha de los indígenas por preservar sus tierras hasta nuestros días. A pesar de que estos pueblos han sido dramáticamente reducidos aún ocupan parte del territorio.

En términos generales, varios factores motivaron que el resguardo entrara en proceso de remate, pero solo uno fue contundente, la visita y las ordenes de Francisco Moreno y Escandón cumpliendo un mandato de los reyes de España. Este hecho permitió que el resguardo de Ubaté entrara en un proceso de reducción de las tierras, lo que originó el traslado de los indios que habían sido llevados a Ubaté.

Por último, se espera que el aporte histórico sobre esta región sirva de guía a próximos estudios que permitan ampliar el conocimiento de los acontecimientos que allí sucedieron. Se pretende que la consulta de las fuentes primarias que ofrecen los archivos históricos pueda despertar el interés de los nuevos investigadores en la construcción y revisión de la historia colonial. Esto deberá contribuir a la construcción de una historia moderna contada desde otra perspectiva, permitiendo realzar histórica y documentalmente el valor de una nación.

\section{FUENTES PRIMARIAS}

AGN, 1592, Sección Colonia. Fondo: Visitas. Subfondo: visitas de Cundinamarca. Legajo No: 2 Folio 173r. Ubaté: investigaciones sobre administración de encomendero.

AGN, 1657, Sección Colonia. Fondo: Caciques e indios. Folios: 941r. Legajo No 18: Partido de Ubaté: nombramiento de Corregidor de Indios.

AGN, 1746, Sección Colonia. Fondo: Caciques e Indios. Legajo No: 21. Folios: 382r y 382 v. Ubaté: intromisión de blancos en tierras de indios.

AGN, 1789, Sección Colonia. Fondo: Caciques e indios. Legajo No: 10. Ubaté: Propiedad hacienda de Niuque. Folios: 251r.

AGN, 1800, Sección Colonia. Fondo: Colegios. Legajo No: 1. Folios: 2r... Ubaté: deslinde de resguardos indígenas.

AGN, Colonia, sección: Mapas y Planos. Mapoteca Ref.- 328 A. 


\section{REFERENCIAS}

Bonnet Vélez, D. (2002). Tierra y comunidad: un problema irresuelto. El caso del altiplano cundiboyacense (Virreinato de la Nueva Granada) 1750-1800. Bogotá: Universidad de los Andes.

Colmenares, G. (1999). Historia económica y social de Colombia: 1537-1719, Tomo 1. Bogotá: Tercer Mundo.

González, M. (1992). El resguardo en la Nueva Granada. Bogotá: El Áncora.

Herrera, M. (1996). Poder local, población y ordenamiento territorial en la Nueva Granada, siglo XVIII. Bogotá: Archivo General de la Nación.

Herrera, M. (2002). Ordenar para controlar: Ordenamiento espacial y control político en las neogranadinos, siglo XVIII llanuras del Caribe y en los Andes centrales. Bogotá: Universidad de los Andes.

Levi, G. (1990). La herencia inmaterial. La historia de un exorcista piamontés del siglo XVII. Madrid: Nerea.

Mörner, M. (1963). Las Comunidades de Indígenas y la Legislación Segregacionista en el Nuevo Reino de Granada. Anuario Colombiano de Historia Social y de la Cultura, 1(1), p. 63-88

Tovar Pinzón, H. (1982). El Estado colonial frente al poder local y regional. Nova Americana, 5, 39-77. 